\title{
Seasonal Occurrence of Marine Mussel Plantigrades in Tokyo Harbor*1
}

\author{
Takeshi KaJIHARA*2 and Minako OKA ${ }^{* 2}$ \\ (Received September 5, 1979)
}

\begin{abstract}
A large bed of marine mussel, Mytilus edulis galloprovincialis LAMARCK, has formed in the intertidal zone of Tokyo Bay. In studying the ecology of the mussel in Tokyo Bay, the seasonal occurrence of planktonic larvae and the settlement of young mussels were investigated. Hydrozoa was used as a natural substratum. As an artificial substratum, a rope collector made of filaments of vinilon rope was used. Planktonic larvae appeared all through the year except during the season from late June to September, with the peak in late March. The kinetics of settlement on hydrozoa and the rope collector was almost the same as that of the appearance of planktonic larvae, with the peak in late April. A few settlements were observed on the hydrozoa and the rope collector during the summer. Most settlements on the rope collector were observed at a depth of $2 \mathrm{~m}$ below $\mathrm{CD}$. As a substratum for primary settlement, the rope collector seems to be very useful for monitoring the seasonal occurrence of young mussels.
\end{abstract}

There have been some reports on the spawning and the settlement of marine mussel, Mytilus edulis galloprovincialis LAMARCK, in the coast around $\operatorname{Japan}^{1-5)}$. However, there is little information on the seasonal occurrence of the primary settlement of plantigrades in connection with the occurrence of planktonic larvae, which is very important in studying the population dynamics of the mussels. The primary settlement preferentially occurs on filamentous substrata such as algae and hydrozoa. ${ }^{6,7)}$ Subsequently, plantigrades attach to and detach from substrata in the sea until they find a suitable place for final settlement ${ }^{8)}$. Some authors attempted the use of artificial collectors for collection of mussel spats ${ }^{9-11 !}$.

The seasonal occurrences of planktonic larvae and primary settlement of the mussel were investigated at Harumi pier (the depth of $4 \mathrm{~m}$ below $C D$, Chart Datum) in Tokyo Harbor during the period from November 1977 to November 1978. For this study in Tokyo Harbor, filaments of vinilon rope were used as the artificial substratum and compared with the natural substratum, hydrozoa. At the same time, planktonic larvae were sampled. Most of the coast along the Tokyo Bay is covered with a concrete wall of jetties and piers, in the littoral zone of which a large mussel zone is formed. In Tokyo Harbor, which is situated at the innermost part of Tokyo Bay, water temperature and salinity are the most changeable of the entire bay $^{5 !}$.

\section{Materials and Methods}

The planktonic larvae and young mussels settled on hydrozoa and artificial collectors were collected twice a month throughout this study. Plankton samples were obtained quantitatively with a plankton net $(\phi: 30 \mathrm{~cm}$, mesh size: XX13) by hauling $50 \mathrm{~m}$ of the surface water. Hydrozoa (Eudendrium spp.) were sampled from a rope which had been suspended perpendicularly from the pier more than six months. The sampling depth of hydrozoa was about $2 \mathrm{~m}$ below $\mathrm{CD}$. The artificial collector, rope collector, was made of vinilon rope (trade name: Klemona, $\phi: 5 \mathrm{~mm}$, length: $35 \mathrm{~cm}$ ), which was unwound $10 \mathrm{~cm}$ from the end so that it would collect the spats of mussel more effectively. The rope collectors were tied to a rope suspended perpendicularly from the pier at the depths of $1 \mathrm{~m}, 2 \mathrm{~m}$ and $3 \mathrm{~m}$ below CD. The rope collector of each depth was sampled after half a month's immersion in the sea. The above samples were preserved in $5 \%$ formalin in sea water. The shell lengths of mussel were measured by an eyepiece micrometer in a binocular microscope. The population densities of planktonic larvae were expressed per $\mathrm{m}^{3}$ of filtered sea

*1 This study was partly supported by a grant from the Ministry of Education (grant No. 136020).

*2 Ocean Research Institute, University of Tokyo, Minamidai Nakano, Tokyo 164 (梶原 武 -岡 美 奈子：東京大学海洋研究所). 
water, and those of young mussels on hydrozoa and the rope collectors were expressed per gram dry weight of the substratum.

\section{Results and Discussion}

The shell lengths in early life of mussel were tentatively divided into seven developmental stages as follows: stage I: $100-124 \mu \mathrm{m}$; stage II: 125-249 $\mu \mathrm{m}$; stage III: $250-499 \mu \mathrm{m}$; stage IV: $500-999 \mu \mathrm{m}$; stage $\mathrm{V}: 1000-1499 \mu \mathrm{m}$; stage VI: 1500-2999 $\mu \mathrm{m}$ and stage VII: 3000-5999 $\mu \mathrm{m}$. Stage I corresponds to D shaped larva, stage II to

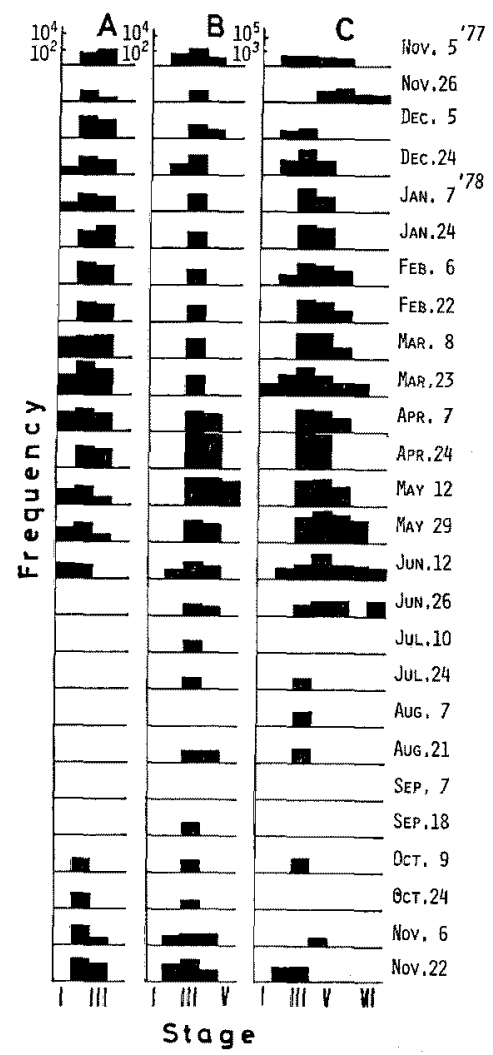

Fig. 1. Occurrence of young Mytilus edulis galloprovincialis in Tokyo Harbor. A: number of planktonic larvae per $\mathrm{m}^{3}$ of filtered sea water, B: young mussels per gram of rope collector at $2 \mathrm{~m}$ depth below $\mathrm{CD}$ and $\mathrm{C}$ : young mussels per gram of hydrozoa. Shell length of each stage is as follows: I: $100-124 \mu \mathrm{m}$; II: $125-249 \mu \mathrm{m}$; III: $250-499 \mu \mathrm{m}$; IV: $500-999 \mu \mathrm{m} ; \mathrm{V}: 1000-$ $1499 \mu \mathrm{m}$; VI: $1500-2999 \mu \mathrm{m}$ and VII: $3000-$ $5999 \mu \mathrm{m}$. veliconcha larva and pediveliger, stage III to early plantigrade and stages IV and $V$ to late plantigrade ${ }^{8 !}$.

The mussels found in the plankton were in stages I-III, those on the rope collector in stages II-V and those on the hydrozoa in stages I-VII (Fig. 1). The planktonic larvae of stage II were most abundant in the plankton. Stage I larvae should have been more abundant in the water, but most of them had slipped out of the mesh of the plankton net. The mussels in stage III appeared both on the rope collector or hydrozoa and in plankton. This indicates that primary settlement occurs during this stage.

On the rope collector the primary settlement of stage III was prominent. The mussels in stage IV, which is regarded as the second pelagic phase, attach and detach repeatedly until they find suitable substrata for adult life ${ }^{7}$, but they did not appear in the plankton. Therefore, most of the individuals in stage IV found on the rope collector probably settled there when they were in stage III. This viewpoint is reasonable because none in stage IV appeared during the low water temperature season.

Figure 2 shows the seasonal occurrences of

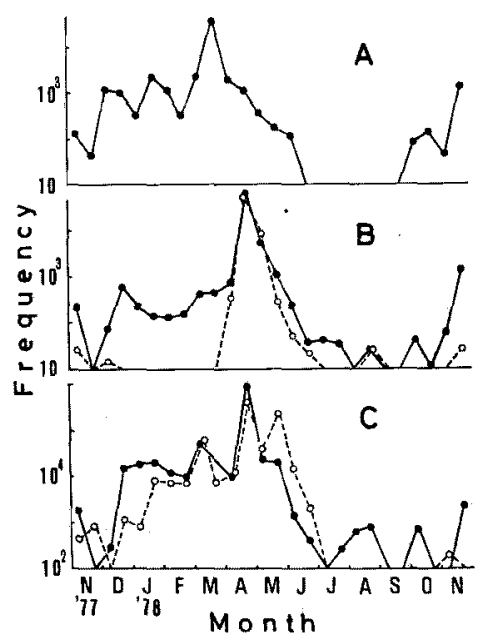

Fig. 2. Seasonal occurrence of young Mytilus edulis galloprovincialis in Tokyo Harbor. A: number of planktonic larvae per $\mathrm{m}^{3}$ of filtered sea water, $B$ : young mussels per gram of rope collector at $2 \mathrm{~m}$ depth below $\mathrm{CD}$ and $\mathrm{C}$ : young mussels per gram of hydrozoa. The solid line indicates shells less than $500 \mu \mathrm{m}$ and the broken line shells from 500 to $1500 \mu \mathrm{m}$. 
planktonic larvae, early and late plantigrades in plankton, rope collector and hydrozoa. The planktonic larvae appeared during the period from October to next June. However, some settlement was observed on the rope collector and hydrozoa even in summer. This suggests that during the summer there were a few spawning, but the pelagic larvae were not caught in the plankton net. The peak of the occurrence of planktonic larvae was in late March, and those of early plantigrades on the rope collector and hydrozoa occurred in late April. This indicates that the occurrence of planktonic larvae was followed by the primary settlement on the rope collector and hydrozoa, and plantigrades appeared on the filamentous substrata about one month after the occurrence of planktonic larvae. And it is estimated that the interval between the peak of primary settlement on the filamentous substrata and that of settlement of young mussels less than $3 \mathrm{~mm}$ in shell length to the adult mussel beds is about one month at Harumi pier ${ }^{5)}$.

The stage range of the mussels found on the hydrozoa was considerably wider than on the rope collector (Fig. 1). The settling period of late plantigrade was longer on the hydrozoa than on the rope collector (Figs. 1, 2). The individuals of the younger stages, which were found on the hydrozoa but not on the rope collector, may have been trapped by the twigs of the hydrozoan colonies since they have a much more complicated structure than the rope collector. There may be several reasons for the frequent appearance of the larger mussels on the hydrozoa, but not on the rope collector. The hydrozoan colony grows rapidly and its life span is generally more than one month. Therefore, plantigrades may be able to spend more long time on the hydrozoa than on the rope collector. The second reason may be that, since hydrozoa directly attach themselves to the rope suspended from the pier, there is more chance for large mussels to move from the rope to the hydrozoa. Still another reason may be that hydrozoa have such a complicated structure that there are various sizes of concaves preferred by larger mussels as well as small ones. And if larger mussels happen to attach on the hydrozoa, they will not move away. As a settling substratum, the artificial substratum, the rope collctor, differs from the natural hydrozoa in some characters. It seems to be the preferred substratum for the primary settlement larvae.

To check the effect of depth on the settlement,

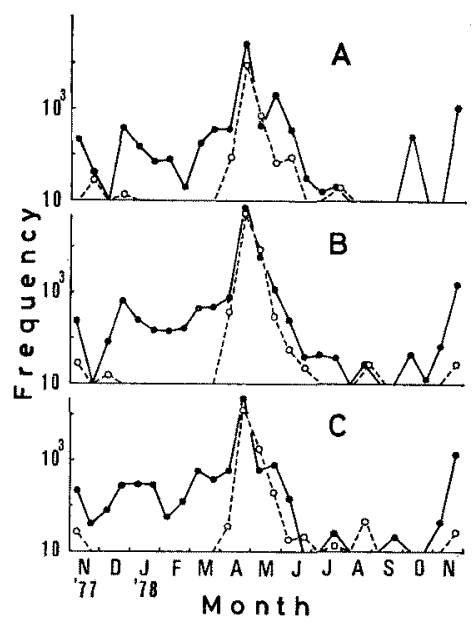

Fig. 3. Seasonal occurrence of young Mytilus edulis galloprovincialis on the rope collector at different depths in Tokyo Harbor. A: $1 \mathrm{~m}, \mathrm{~B}: 2 \mathrm{~m}$ and C: $3 \mathrm{~m}$ depth below $C D$. Number of young mussels is expressed per gram of rope collector. The solid line indicates shells less than $500 \mu \mathrm{m}$ and the broken line shells from 500 to $1500 \mu \mathrm{m}$.

the rope collectors were immersed at three different depths for about half a month and the seasonal occurrences of early and late plantigrades were compared in Figure 3. There is little difference in the tendency of occurrence of mussel spats at different depths, but the total numbers of spats throughout this study were most aboundant at $2 \mathrm{~m}$ depth (average number per gram of rope: about 5800 at $2 \mathrm{~m}$ depth, about 1700 at $1 \mathrm{~m}$ and $3 \mathrm{~m}$ depths). This trend was prominent in the peak season. Therefore, when using a rope as the collector, the depth of $2 \mathrm{~m}$ below $\mathrm{CD}$ seems to be favorable for the settlement of plantigrade in this studying site.

Up to the present, not a few substrata have been examined for the settlement of mussels. However, natural substrata are not suitable for quantitative analysis because they are of more or less complicated structure, and because the number of settlements and the size of the shells preferentially settled differ for each kind of substratum ${ }^{\text {' }}$. Therefore, the settlement of different substrata cannot be compared in the strict sense. And also it is difficult to observe the settlements where the natural substratum does not grow. The rope collector compensates for these demerits of natural substrata, because the rope collector has a simple and uniform structure and is useful for the experimental exposure at places or seasons which natural 
substrata cannot be found. Morever, the results of this study showed that the rope collector was especially good for the primary settlement of the mussels.

\section{References}

1) I. MrYazaKi: Bull. Japan. Soc. Sci. Fish., 6, 223232 (1938).

2) Y. SugruRa: Bull. Japan. Soc. Sci. Fish., 25, 1-6 (1959).

3) T. KaJhara: Bull. Fac. Fish. Nagasaki Univ., 16, 1-138 (1964).

4) T. YasUdA: Aquiculture, 15, 31-38 (1967).
5) T. KaJiHara, Y. URA, and N. ITo; Bull. Japan. Soc. Sci. Fish., 44, 949-953 (1978).

6) J. VeRweY: Arch. Neerl. de Zool., 10, 171-239 (1952).

7) B. L. BAYNE: J. Animal Ecol., 33, 513-523 (1964).

8) B. L. BAYNE: in "Marine mussels", (ed. by B. L. Bayne), Cambridge Univ. Press, Cambridge, 1976, 81-120.

9) J. W. De Blok and H. T. Geelen: Arch. Neerl. de Zool., 13, 446-460 (1958).

10) B. BøHLE: in "Fourth European marine biology symposium", (ed. by D. J. CRISP), Academic Press, London, 1971, 63-69.

11) G. Davies: J. Cons. int. Explor. Mer., 36, 27-34 (1974). 